\section{Gupta affirms authenticity}

\section{New Delhi}

Professor V.J. Gupta, of the Panjab University at Chandigarh, has angrily denied charges by Dr John Talent in last week's Nature $(\mathbf{3 3 8}, 613 ; \mathbf{1 9 8 9})$ that he invented fictitious fossils and had rewritten the geological history of the Himalayas through dubious publications. Gupta claimed that Talent's outburst was motivated by "a malicious intent to take revenge for personal rivalry and professional jealousy over the past 20 years".

Gupta did not specify Talent's motives for revenge, but implied that his interest in the Himalayas went beyond geology, and that the attack on him had something to do with information he was unable to provide to Talent. Gupta said his fossil collections came from Himalayan sites that were either militarily sensitive or close to international borders and thus not open to foreigners.

According to Gupta, Talent and his associates "wanted some information [about localities] which we cannot provide [for security reasons]". He said that Talent visited India 20 times "always entering from Pakistan", but says that he did not publish any paper on India. "I wonder which agency would finance a scientist for so many travels that result in no scientific output?" he asked.

On the authenticity of his fossils, Gupta says they were dug out by a team, not by him alone. To get them identified, expert opinions were sought from palaeontologists abroad. In some cases, opinions were contradictory, but "the diverse opinions were kept in view while working out the stratigraphic set-up of the area, taking account of the geological succession exposed in the field from where the fossils were collected". He said Talent was biased in his opinion about the ages of stratigraphic units.

Replying to the charge that his details of the localities at which his fossils were collected are distorted, Gupta said he had had to depend on old and inaccurate maps whose use is restricted by the government for security reasons. Gupta said his 25 years of work has documented the existence of Silurian-Devonian succession in the Himalayas and that "the truth about it will be proved by the progeny during the forthcoming years".

Predictably, the Talent-Gupta controversy has evoked a spate of comments from Indian scientists and hurried meetings at the Indian Geological Survey. Gupta's colleagues at the Centre for Advanced Study in Geology, including its director, Dr A.K. Prasad, described Talent's allegations as "a conspiracy to denigrate a top Indian scientist".

But the Society for Scientific Values (SSV) plans to launch its own investiga- tion of the allegations. Describing them as "serious and undermining of Indian science", the society's president, Dr A.S. Paintal, said it will appoint an expert team to make an impartial evaluation of Gupta's work.

Contrary to Talent's implied remarks, CFCs

\section{Tokyo}

JAPAN will support a total ban on the use and production of chlorofluorocarbons (CFCs) by the year 2000, Japan's Environment Agency announced last week.

Japan's decision, to be formally announced next month in Helsinki at a meeting of signatories of the Montreal Protocol, follows similar pledges to end the use of CFCs made last month by the United States, the European Community and Canada (see Nature 338, 101; 1989). Japan's support will be important for the success of a total ban as it is one of the largest producers of CFCs, accounting for about 10 per cent of world production.

The Environment Agency has been keen to support revision of the Montreal Protocol and the announcement represents a victory over the powerful Ministry of International Trade and Industry (MITI). MITI is concerned that Japan's semiconductor industry may be seriously affected by a ban. Japan is the world's largest consumer of freon 113, the CFC used to clean semiconductors, and produces approximately 130,000 tonnes annually. Alternatives to

\section{Tucson}

Congressional legislation that would make it a federal crime to steal or harm research animals or to break into and damage research facilities was introduced on 7 April in the US Senate.

Alabama Democrat Howell T. Heflin proposed the Animal Research Facility Protection Act of 1989 so that federal law enforcement agencies can become involved against what he said could be an international conspiracy.

During the next month, the Senate Committee on Agriculture, Nutrition and Forestry will review the bill, which will be an amendment to the Animal Welfare Act. Passage into law could take more than a year. The legislation also makes unauthorized entry into facilities and possession, control or duplication of records, data, material, equipment or animals a possible federal offence. Each violation could lead to a one-year prison sentence and a $\$ 5,000$ fine. The district court or magistrate could force the guilty party to
India does have a mechanism to check fraudulent research, said Paintal, who is also chief of the Indian Council of Medical Research. With a membership of over 120 reputable scientists, SSV was set up two years ago with the aim of improving the quality of science in India. So far, it has been concerned largely with allegations of misconduct in biomedical research.

K.S.Jayaraman

\title{
Japan supports ban by the year 2000
}

freon 113 are still in the early stages of development.

The machinations that led to the Environment Agency victory are unknown, but the words of an eminent foreign scientist and Japan's emperor may have helped.

Earlier this month, Frank Sherwood Rowland of the University of California, who was in Tokyo to receive the Japan Prize for his pioneering research on the link between CFCs and ozone depletion, repeatedly called for a worldwide ban. His appeals received wide media coverage.

At the presentation ceremony for the prize, the Emperor in a congratulatory speech noted that when CFCs were first synthesized for practical application, no one suspected that they would have such "dire consequences" he said that this should be a reminder that "science and technology need to be constantly monitored and appraised from newer and wider perspectives".

It is unusual for a Japanese emperor to make a public statement on such a politically sensitive subject. Following such a speech it would have been odd if Japan had not supported a ban.

\section{Anti-terrorism bill introduced in Senate}

pay for damages and for reasonable cost of repeating ruined experiments. The research institution could also sue for damages.

The legislation also calls for the Secretary of Agriculture and the attorney general to assess the extent and effects of "domestic and international terrorism" on animal research, production and processing facilities. That survey would include places where animals are on exhibit or used in food production or as pets. A report would be due within a year.

Heflin said he had been working on the bill for several months at the insistence of the University of Alabama in Birmingham, but that a recent incident at the University of Arizona in Tucson (see Nature 338, 534; 1989) "acted as a catalyst to bring about a more rapid introduction than we had planned". In that incident, a group calling itself the Animal Liberation Front set fires in two university buildings, vandalized laboratories in two other buildings and took about 1,200 small animals.

Elizabeth Pennisi 